\title{
Göran Frostell: A Grand Old Man in Swedish Preventive Odontology
}

Prof. em. Göran Frostell has passed on in Djursholm, Stockholm, Sweden, in February 2020, 99 years old. He graduated as a dentist and medical doctor at Karolinska Institutet. After several years as a teacher and scientist at the Dental School in Stockholm, he became Head of the Oral Microbiology Laboratory. In 1970, he was appointed as Professor and Chairman of the Department of Cariology in Malmö, and was Dean at the Dental School from 1976 to 1977. In 1977, he became Professor in Cariology at Karolinska Institutet in Stockholm.

Göran Frostell was tutor for several PhD students and published more than 100 scientific articles, 12 of these in the journal Caries Research. He also wrote textbooks and chapters in Oral Microbiology and Cariology. His two most cited publications are (1) "Effect of various sugars and sugar substitutes on dental caries in hamsters and rats" in collaboration with Paul Keyes and Rachel Larson, published in the Journal of Nutrition in 1967 (164 citations), and (2) "A method for evaluation of acid potentialities of foods", published in Acta Odontologica Scandinavica in 1970 (94 citations). Göran Frostell's main research interest was sugar substitutes, and he conducted several animal and long-term clinical studies on invert sugar and lycacin. He collaborated with researchers in the USA (Forsyth Dental Center) and Japan (Tokyo Dental College).

In collaboration with Prof. Yngve Ericsson, he established the "Swedish Patent Revenue Fund for Research in Preventive Odontology" in 1963, which has been an important promotor of prevention in Scandinavia and Europe. Since 1988, the "Yngve Ericsson Prize for Research in Preventive Odontology" is awarded every 3 years in

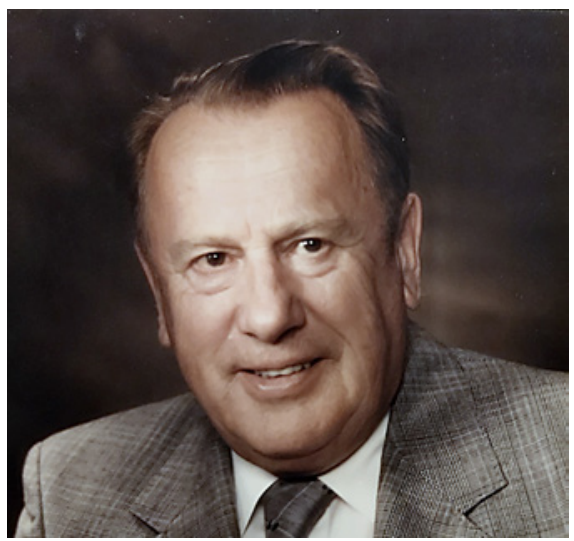

Göran Frostell

acknowledgement of outstanding scientific contribution to the prevention of oral diseases. For some years, this prize has been awarded in collaboration with the European Organization for Caries Research (ORCA). Up to now (1988-2019), the prize has been awarded to 11 pairs of researchers in cariology and periodontology (http:// pmf.se/yngve-ericssons-pris.html).

At younger age, Göran Frostell was an adventurous sailor, and he will also be remembered as the exciting story teller, generously entertaining his friends with barely believable episodes. Göran Frostell leaves four children and their families behind.

Birgit Angmar-Månsson, Prof. em.,

Karolinska Institutet

Dowen Birkhed, Prof. em., Sahlgrenska Academy Carolina Ganss, Prof., Editor, Caries Research Christian Splieth, Prof., President, ORCA 